\title{
Oxidative Stress and Neuronal NOS Activity: Putative Determinants of Rapid Blood Pressure Increase After Renal Denervation in Anesthetized Rats
}

\author{
A. WALKOWSKA ${ }^{1}$, J. SADOWSKI ${ }^{1}$, E. KOMPANOWSKA-JEZIERSKA ${ }^{1}$ \\ ${ }^{1}$ Department of Renal and Body Fluid Physiology, Mossakowski Medical Research Centre, Polish \\ Academy of Sciences, Warsaw, Poland
}

Received September 18, 2012

Accepted January 3, 2013

On-line March 14, 2013

\section{Summary}

Long-term effects of renal denervation (DNX) commonly include a decrease in blood pressure (BP), observed in both normotensive animals and various models of hypertension. On the other hand, short term BP responses vary. We examined how post-DNX increase in BP observed in this study depends on baseline metabolic and functional status of animals, with a special interest for the role of oxidative stress. Anesthetized Wistar rats on standard (STD), low-sodium (LS) or high-sodium (HS) diet were used, untreated or pre-treated with tempol, a superoxide scavenger, or N(omega)-propyl-L-arginine (L-NPA), an inhibitor of neuronal NOS (nNOS). Early BP and renal hemodynamic responses were examined to right- and then leftside DNX performed using an own relatively non-invasive technique. Left kidney cortical, outer- and inner-medullary blood flows (CBF, OMBF, IMBF) were continuously recorded as laserDoppler fluxes. Sequential denervations significantly increased BP to final $19 \%, 12 \%$, and $6 \%$ above control level in HS, LS, and STD groups, respectively. CBF, a measure of total renal perfusion, increased in LS and STD but not in HS rats. Tempol pretreatment prevented the post-denervation BP increase on each diet. Selective inhibition of nNOS prevented BP increase in STD and HS groups, a modest increase persisted in LS rats. We propose that enhanced afferent impulsation from intrarenal chemoreceptors related to oxidative stress in the kidney was the background for acute BP increase after DNX. The response was triggered by a release of brain sympatho-excitatory centers from inhibition by renal afferents, this was followed by widespread sympathetic cardiovascular stimulation.

\section{Key words}

Nitric oxide • Renal denervation • Free radicals

\section{Corresponding author}

A. Walkowska, Department of Renal and Body Fluid Physiology, Mossakowski Medical Research Centre Polish Academy of Sciences, Pawińskiego 5, 02-106 Warsaw, Poland. E-mail: agnieszkawalkowska@gmail.com

\section{Introduction}

Complex interrelation of renal nerve activity and cardiovascular functions determining arterial blood pressure (BP) has been studied in detail over the past decades and was the subject of a number of reviews (DiBona and Kopp 1997, Stella and Zanchetti 1991, Bie 2009, Pintérová et al. 2011). The long-term effect of renal denervation was usually a decrease in $\mathrm{BP}$, as was documented in normal rats (Jacob et al. 2003, Kompanowska-Jezierska et al. 2008) and in various models of hypertension (Liard 1977, Wyss et al. 1992, Campese and Kogosov 1995). This was an expected phenomenon, given the stimulatory influence of renal sympathetic nerve activity (RSNA) on tubular reabsorption, renin release and renal vascular tone, and the crucial role of renal excretion in control of body fluid volume. By contrast, rapid cardiovascular and BP responses to changes in afferent and/or efferent renal sympathetic nerve activity were not uniform. This is not surprising since there is evidence that the effect of renal afferent impulse traffic on brain cardiovascular centers 
which control peripheral vascular resistance and BP may be either excitatory or inhibitory (reviewed in Stella and Zanchetti 1991). Selective electrical stimulation of renal afferents was reported to induce a decrease in BP in anesthetized rats (Lappe et al. 1985, Webb and Brody 1987, Herman and Kostreva 1996), which was ascribed to inhibitory influence of the afferent traffic on sympathetic centers controlling cardiovascular functions. On the other hand, renal denervation (DNX) did not usually induce short-term BP elevation (Kline et al. 1980, Winternitz et al. 1980). It was suggested that under the experimental conditions applied there was no tonic inhibitory influence on brain sympathetic centers (Stella and Zanchetti 1991). In this study we attempted to define the basal circumstances which might unmask the role of renal afferents in cardiovascular control.

As suggested above, the baseline level of RSNA, especially of the afferent traffic, is likely to affect cardiovascular response to DNX. Since this basal activity may depend, among other factors, on the metabolic status of the kidney which is strictly coupled to renal sodium handling, we examined BP responses in rats on either low or high sodium intake. An important feature of tissue metabolism under normal and pathologic conditions is the level of reactive oxygen and NO radicals (Wilcox 2005, Vanhoutte et al. 2009) To test if oxidative stress was, indeed, a crucial factor determining a possible pressure response to DNX, we repeated experiments after having scavenged the superoxides $\left(\mathrm{O}_{2}^{-}\right)$using tempol. Moreover, considering complex interaction of the autonomous nervous system activity and generation of ROS and nitric oxide (Xu et al. 2001, Wilcox 2005), we also examined how the response to DNX is affected by inactivation of neuronal NOS (nNOS), the isoform which, under conditions of oxidative stress may be an important source of ROS (Edlund et al. 2010). It is noteworthy that nNOS is also the isoform which prevails in the brain and influences the function of both central sympatho-excitatory neurons and peripheral sympathetic nerve endings, e.g. in the vascular wall. To reduce the risk of transient stimulation of nerve fibers during denervation procedure, a crucial issue when short-time responses are studied, we applied here a relatively non-invasive technique which was proven to enable reliable renal hemodynamic measurements in the early postdenervation period (Kompanowska-Jezierska et al. 2001).

\section{Material and Methods}

The experimental procedures were in accordance with the Guide for the Care and Use of Laboratory Animals, NIH (Bethesda 1985) and were also approved by the extramural IV Local Ethical Committee, Warsaw. Male Wistar rats were fed a standard diet (STD, $0.25 \%$ $\mathrm{Na} w / \mathrm{w}$ ) or, for 3 weeks, a low-sodium (LS, $0.15 \% \mathrm{Na}$ $\mathrm{w} / \mathrm{w}$ ) or high-sodium (HS, $4 \% \mathrm{Na} w / \mathrm{w}$ ) diet (SSNIFF $\mathrm{GmbH}$, Soest, Germany). Our previous experience has shown that although in terms of $\mathrm{Na}$ concentration the difference between STD and LS diet is small, effects on renal sodium handling and body sodium status are remarkably different. The rats were anesthetized with intraperitoneal sodium thiopental (Sandoz GmbH, Kundl, Austria), $100 \mathrm{mg} \mathrm{kg}^{-1}$, which provided stable anesthesia for about three hours. The animals were placed on a heated surgery table to maintain rectal temperature at about $37^{\circ} \mathrm{C}$. A tracheal cannula ensured free airways. The femoral vein was cannulated for fluid infusions and the carotid artery for BP measurement (Stoelting blood pressure meter and transducers, Wood Dale, Illinois, USA). During surgery, $3 \%$ bovine serum albumin solution was infused i.v. at $3 \mathrm{ml} \mathrm{h}^{-1}$ to preserve plasma volume.

\section{Experimental procedures}

The right kidney was accessed by flank incision. Stainless steel wire $(0.1 \mathrm{~mm}$ in diameter $)$ was used to form a loop which was placed around the fat and connective tissue located cephalad to the right renal artery-aortic junction. Dissection studies had shown that this tissue encompassed most of renal nerve fibers traveling from the coeliac ganglion to the kidney (Kompanowska-Jezierska et al. 2001). The loop was threaded through a segment of thick-walled PE tubing, and left loose, prepared for later right-side DNX. Subsequently, the left kidney was exposed from flank incision and immobilized in a plastic holder. Another wire loop was placed around the tissue encompassing the nerves, to prepare for left DNX. The effectiveness of this denervation technique was confirmed by demonstration of the depletion of renal tissue noradrenaline content to $<5 \%$ of control as well as of an acute rapid increase in $\mathrm{CBF}$ (confirmed also in the present study) and of distinct denervation natriuresis (Kompanowska-Jezierska et al. 2001). A laser-Doppler probe, type PF 407, was placed on left kidney surface to record superficial cortical laserDoppler blood flow (CBF). Outer medullary blood flow 
(OMBF) and inner medullary blood flow (IMBF) were measured using needle probes ( $\mathrm{PF} 402$ ) inserted to the respective depths of 3 and $5 \mathrm{~mm}$ from kidney surface. The probes were connected with a three-channel Periflux 5010 flow-meter (Perimed, Jarfalla, Sweden). Other details of the experimental techniques were described previously (Kompanowska-Jezierska et al. 2001, Kompanowska-Jezierska et al. 2008).

After placement of wire loops for denervation, flow probes in the left kidney, and after stabilization of the parameters measured, control values were recorded during $30 \mathrm{~min}$. Subsequently, right-side DNX was performed. At first, $1 \%$ novocain solution was injected into the PE tubing segment containing the wire loop, to provide a gradual rather than abrupt interruption of conduction in the renal nerves and prevent transient stimulation of nerve fibers (Kompanowska-Jezierska et al. 2001). The loop was tightened and the tissue within was cauterized using a $5 \mathrm{MHz}$ current generated for 5$10 \mathrm{~s}$ using a neurosurgical cautery device (Famed, Warsaw, Poland). Five minutes later a 30-min experimental and measurement period was made. Thereafter left DNX was performed, followed by another 30-min observation period. In two rats on STD diet and three rats on HS diet the observation period after left-side DNX was prolonged to a total of $60 \mathrm{~min}$. The averaged data for the last five min of each post-denervation period were taken as a final result of DNX I (right-side) and DNX II (left-side) and shown in figures. While the standard denervation technique involves cutting the nerve fibers adjacent to the renal artery and damaging those in the artery wall using phenol, our approach interrupts neural conduction distant from the artery, whereby the usual vessel spasm and derangement of intrarenal circulation is avoided. This enables starting experimental measurements within a few minutes post-denervation.

It will be noticed that within the experimental design applied here the renal hemodynamic parameters are determined in the left kidney only; consequently, the responses to right-side denervation (DNX I) are those of the contralateral innervated kidney and the responses to DNX II are simply those of ipsilateral denervation. Three groups of rats were examined within the protocol described above, on each of the three diets. Group 1. Untreated rats (LS: $n=6$; STD: $n=7$; HS: $n=7$ ), group 2. Rats pretreated with $\mathrm{N}($ omega)-propyl-Larginine (L-NPA, Tocris, UK), a selective inhibitor of nNOS, infused i.v. at $1 \mathrm{mg} \mathrm{kg}^{-1} \mathrm{~h}^{-1}$ (Kakoki et al. 2001) (LS: $\mathrm{n}=7$; STD: $\mathrm{n}=5$; HS: $\mathrm{n}=5$ ), and group 3. Rats pretreated with 4-hydroxy-Tempo (Tempol, Sigma, USA), a scavenger of $\mathrm{O}_{2}$, infused i.v. at $12 \mathrm{mg} \mathrm{kg}^{-1} \mathrm{~h}^{-1}$ (LS: $\mathrm{n}=6$; STD: $\mathrm{n}=6$; HS: $\mathrm{n}=5$ ).

In groups 2 and 3, after a control period, about 40 min were allowed from the start of L-NPA or tempol infusion, for stabilization of the variables measured. For sham denervation $(\mathrm{STD}, \mathrm{n}=5)$, fat and connecting tissue in the area caudal to the kidney were cauterized.

In a part of experiments with LS and HS rats arterial blood samples were taken for determination of plasma renin activity by antibody-trapping technique (Poulsen and Jorgensen 1974).

\section{Statistics}

Significance of changes within one group over time was first evaluated by repeated measurement analysis of variance (ANOVA), followed by modified $\mathrm{t}$ statistics for dependent variables. Differences between groups were first analyzed by the classical one-way ANOVA, followed by Bonferroni's tests for multiple comparisons.

\section{Results}

After right-side and left-side DNX, BP almost always showed a progressing increase. Figure 1 shows $\mathrm{BP}$ and renal cortical blood flow (CBF) changes after sequential denervation procedures in rats on standard, low and high sodium intake (LS, STD, HS). In LS and HS rats bilateral DNX increased BP 12 and $19 \%$, respectively; significant increases were seen already after unilateral (right-side) denervation. BP elevations were not associated with any changes in heart rate: in the group with greatest responses (HS) it was $365 \pm 5$ before and $366 \pm 7$ beats per min after second denervation $(n=8$, data not shown). Nor were there significant heart rate changes in STD or LS groups. In STD rats no significant change in BP was seen after right-side DNX and the final increase was less than $6 \%$. Both after right-side and leftside DNX, the pressure usually increased progressively during the first $15 \mathrm{~min}$, which was followed by a plateau. Prolongation of observation by an additional $30 \mathrm{~min}$ (to a total of $60 \mathrm{~min}$ after left side DNX) showed that the plateau was maintained over the whole period.

In STD rats, left kidney CBF increased after the right side- and then further after left-side denervation. In the LS group, CBF also increased progressively (ANOVA) but the ultimate change did not reach significance level in a Bonferroni test. Remarkably, in HS 
rats $\mathrm{CBF}$ did not change at all. Both $\mathrm{BP}$ and $\mathrm{CBF}$ remained stable in STD rats subjected to sham denervation. Figure 2 shows that in LS and STD rats,
DNX did not significantly alter perfusion of the inner medulla; IMBF decreased slightly in untreated HS rats. No changes in OMBF were seen (data not shown).

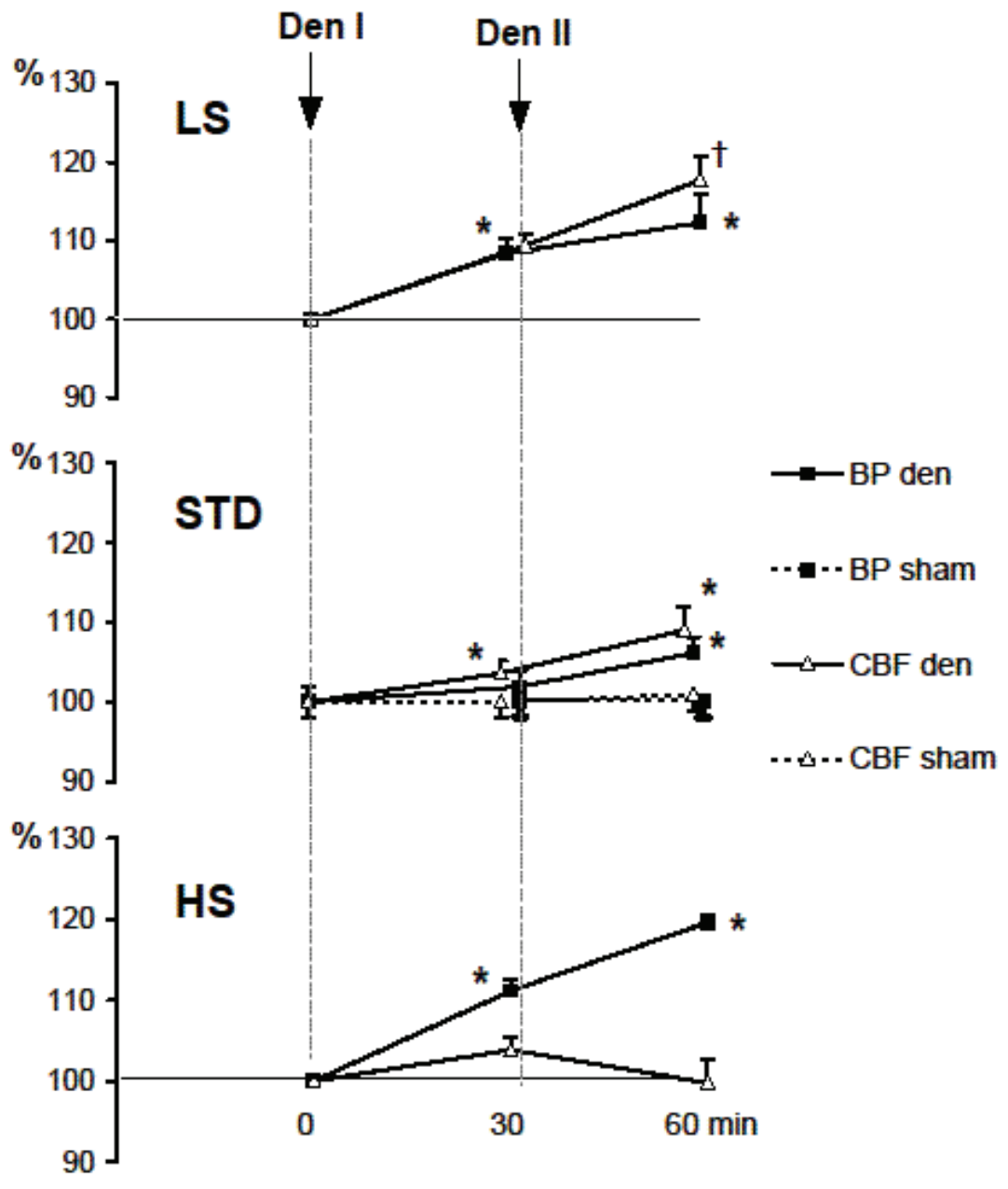

$\Delta \%$
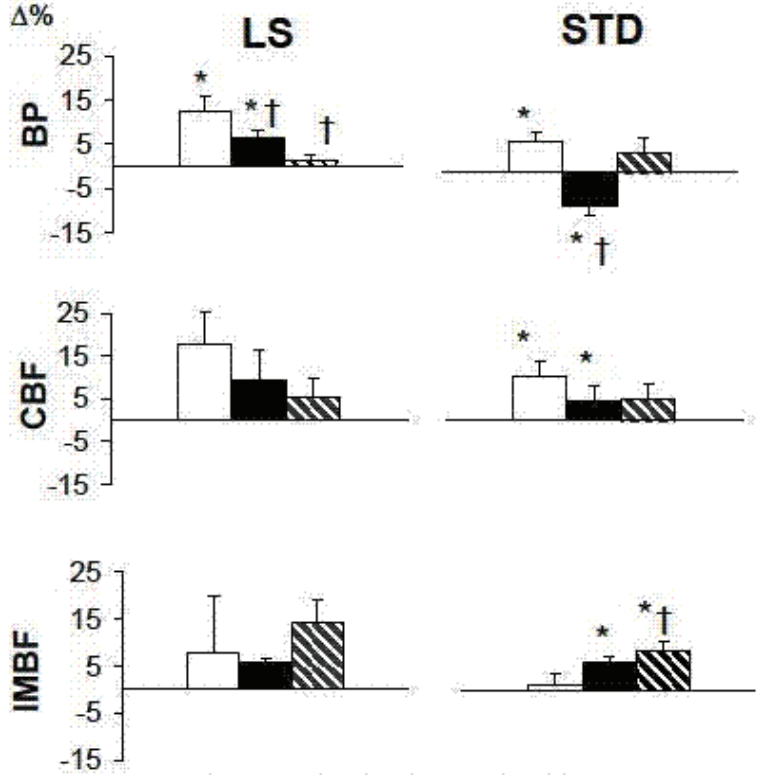

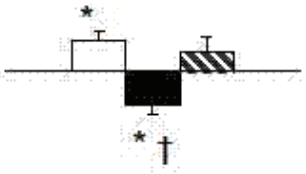

STD

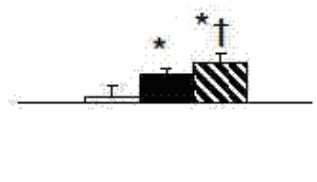

HS
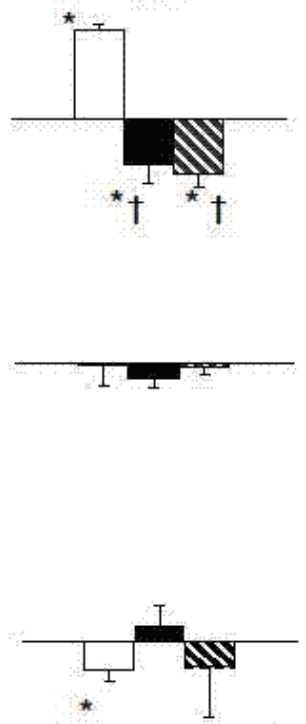

Fig. 1. Effects of sequential right- and left-side renal denervation (Den I, II) on systemic blood pressure (BP) and left kidney cortical blood flow (CBF) in rats on low, standard and high sodium diet (LS, $n=6 ;$ STD, $n=7$ and HS, $n=7$, respectively). Mean $\% \pm$ SEM; sham denervation data for STD group are also shown. * significantly different from pre-denervation control at $\mathrm{p}<0.05$; + significant progressive increase (repeated measurements ANOVA); the final increase did not reach significance level in Student $t$ test $(0.05<p<0.06)$.
Fig. 2. A comparison of final effects of sequential right and left renal denervation on blood pressure (BP) and left kidney cortical blood flow $(\mathrm{CBF})$, and inner medullary blood flow (IMBF) in untreated, L-NPA- or tempol-treated rats (open, black or striped bars, respectively) maintained on low-sodium (LS), standard (STD) or high-sodium (HS) diet. Cumulated percent changes after two denervations are shown, \pm SEM. * significant change from predenervation control at $\mathrm{p}<0.05$; $\dagger$ change from pre-denervation control significantly different from that in untreated rats. $\neq$ change significantly different from that in STD rats $(p<0.02)$. 
Table 1. Effects of Tempol on blood pressure (BP) and perfusion parameters of the left kidney.

\begin{tabular}{|c|c|c|c|c|c|c|}
\hline & \multicolumn{2}{|c|}{ LOW SODIUM DIET } & \multicolumn{2}{|c|}{ STANDARD DIET } & \multicolumn{2}{|c|}{ HIGH SODIUM DIET } \\
\hline & Control & Tempol & Control & Tempol & Control & Tempol \\
\hline$B P(m m H g)$ & $116 \pm 1$ & $111 \pm 3$ & $117 \pm 4$ & $118 \pm 4$ & $126 \pm 5$ & $127 \pm 4$ \\
\hline$C B F(P U)$ & $550 \pm 33$ & $684 \pm 76^{*}$ & $617 \pm 71$ & $700 \pm 76^{*}$ & $801 \pm 86$ & $776 \pm 85$ \\
\hline$O M B F(P U)$ & $143 \pm 26$ & $181 \pm 27^{*}$ & $159 \pm 20$ & $160 \pm 11$ & $194 \pm 39$ & $168 \pm 28$ \\
\hline$I M B F(P U)$ & $140 \pm 8$ & $162 \pm 19$ & $169 \pm 20$ & $175 \pm 28$ & $200 \pm 17$ & $213 \pm 28$ \\
\hline
\end{tabular}

Mean values \pm SEM $(n=5-7)$. CBF, OMBF, IMBF - cortical, outer and inner medullary laser-Doppler fluxes, respectively. PU - perfusion units. * Significantly different from control at $p<0.04$.

Table 2. Effects of L-NPA on blood pressure (BP) and perfusion parameters of the left kidney.

\begin{tabular}{lllllll}
\hline & \multirow{2}{*}{$\begin{array}{l}\text { LOW SODIUM DIET } \\
\text { Control }\end{array}$} & NPA & \multicolumn{2}{c}{ STANDARD DIET } & \multicolumn{2}{c}{ HIGH SODIUM DIET } \\
& & Control & NPA & Control & NPA \\
\hline$B P(m m H g)$ & $120 \pm 3$ & $121 \pm 3$ & $117 \pm 2$ & $119 \pm 3$ & $129 \pm 9$ & $133 \pm 11$ \\
$C B F(P U)$ & $407 \pm 28$ & $412 \pm 39$ & $580 \pm 41$ & $621 \pm 44^{*}$ & $719 \pm 43$ & $679 \pm 48^{*}$ \\
$O M B F(P U)$ & $132 \pm 27$ & $122 \pm 23$ & $260 \pm 21$ & $267 \pm 20$ & $127 \pm 44$ & $134 \pm 45$ \\
$I M B F(P U)$ & $133 \pm 23$ & $121 \pm 23$ & $189 \pm 31$ & $203 \pm 31^{*}$ & $117 \pm 8$ & $137 \pm 17$ \\
\hline
\end{tabular}

Mean values \pm SEM $(n=5-7) . C B F, O M B F, I M B F-$ cortical, outer and inner medullary laser-Doppler fluxes, respectively. PU - perfusion units. * Significantly different from control at $p<0.02$.

The basal plasma renin concentration (PR) on HS diet $\left(10 \pm 2 \mathrm{mIU}^{-1}\right)$ was significantly lower than in LS and STD groups (range of means: 79-81 $\mathrm{mIU}^{-1}$ ). While in both latter groups the basal values were quite comparable, bilateral DNX significantly decreased plasma renin $(-45 \%)$ in LS rats whereas no substantial change $(-6 \%)$ was seen in STD rats.

Pre-denervation $\mathrm{CBF}$ tended to be higher with increasing salt intake (Tables 1,2) Treatment with 4hydroxy-Tempo (tempol), a scavenger of $\mathrm{O}_{2}$ - did not alter BP on any diet (Table 1) but significantly increased CBF in LS and STD groups. OMBF increased in LS rats only. L-NPA, a selective inhibitor of nNOS, did not alter BP on any diet (Table 2). In HS rats L-NPA decreased CBF, which suggested that NO derived from nNOS was on high-salt diet an important factor sustaining renal perfusion. Apparently, this was not so in LS and STD groups where CBF (and IMBF) actually increased after L-NPA.

The final cumulated effect of sequential right and left DNX on BP, and left kidney CBF and IMBF in rats on different diets, untreated or under tempol or LNPA treatment, is presented in Figure 2. The BP increase in untreated HS rats was significantly greater than in the
STD group where it was least pronounced. In LS rats treated with L-NPA the post-denervation increase in BP was significantly smaller than in untreated controls. Remarkably, in STD and HS groups significant decreases occurred.

Bilateral DNX modestly increased CBF in untreated STD and LS (not significant) rats, much less so in rats pretreated with L-NPA. CBF never changed in HS rats.

In rats pretreated with tempol, the postdenervation increases of BP observed in untreated LS and STD rats were abolished. In HS rats, similarly as under L-NPA treatment, a significant decrease occurred. IMBF significantly increased only in STD rats under L-NPA or tempol treatment.

\section{Discussion}

In normotensive anesthetized Wistar rats acute sequential right-side and left-side renal denervation (DNX) induced a rapid progressing elevation of BP. Earlier studies usually revealed no alteration of BP within the first hours post-denervation (Kline et al. 1980, Winternitz et al. 1980). In contrast to these observations, 
the usual long term effect of DNX was BP lowering (Stella and Zanchetti 1991, Jacob et al. 2003), a complex phenomenon obviously related to profound alterations of endocrine and body fluid status. There is no rationale to set aside or directly compare the early and the distant responses to DNX.

Reflex nature of the hypertensive response to renal denervation

The mechanism of the rapid blood pressure elevation after renal denervation is not clear. It is more likely to be neural rather than humoral. Indeed, at least in LS rats, DNX decreased the circulating plasma angiotensin II level, which would have vasodilator and hypotensive rather than hypertensive effects. It will be noticed that the advantage of denervation technique applied here is that no surgical severing of nerve fibers adjacent to the renal artery occurs. This reduces the risk of a BP increase secondary to the artery spasm which is typically observed after the classical DNX manoeuvre; moreover, early fluctuations of renal hemodynamics are avoided and measurements can be conducted immediately (Kompanowska-Jezierska et al. 2001). An obvious disadvantage limiting interpretation of the present results is that the denervation is "complete" i.e. both efferent and afferent.

The data on the reflex influence of renal afferent traffic on the activity of cardiovascular sympathetic centers are ambiguous. Some authors demonstrated excitatory effects, observed in normal animals (reviewed in Stella and Zanchetti 1991) and in some but not in other models of hypertension and renal failure (Wyss et al. 1992, Campese and Kogosov 1995). On the other hand, there is ample evidence on the sympatho-inhibitory influence of the renal afferent traffic. Unilateral afferent or complete DNX increases efferent sympathetic input to the contralateral kidney within the reno-renal reflex phenomenon, leading, on this side, to antidiuresis and antinatriuresis, occasionally to increased renin release and only infrequently to renal vasoconstriction (Colindres et al. 1980, DiBona and Rios 1980, DiBona and Kopp 1997). The likely mechanism of this reflex is the removal of inhibition of central sympatho-excitatory centers controlling sympathetic input to the kidney. However, as was considered more than two decades ago, "renorenal reflexes can be just one part of more generalized sympathetic reflex originating from the kidney" (Stella and Zanchetti 1991). Consistent with this notion are the reports that selective electrical stimulation of renal afferents induced a decrease in BP in anesthetized rats, the response that was prevented by lesion of the nucleus tractus solitarii and the median preoptic nucleus, the centers involved in cardiovascular control (Lappe et al. 1985, Webb and Brody 1987). Most recently, afferent intrarenal nerve stimulation in Sprague-Dawley rats using local capsaicin infusion was shown to reduce the contralateral renal integrated sympathetic nerve activity to about $20 \%$ of the pre-stimulation control value (Ditting et al. 2012).

We propose that in the present experiments the crucial factor for the post-denervation increase in BP was renal de-afferentation. The consequent elimination of the inhibitory influence on the central sympatho-excitatory neurons increased the efferent sympathetic traffic to extrarenal sites, leading to rapid systemic vasoconstriction and an increase in BP. Admittedly, measurements of peripheral sympathetic nerve activity (SNA) would be needed to support this hypothesis. It is remarkable that the $\mathrm{BP}$ elevation after DNX observed here in male Wistar rats was not reproduced in our study using female Sprague-Dawley rats, in which a more usual decrease in blood pressure was seen (KompanowskaJezierska et al. 2008). In both studies the same noninvasive DNX method was used, which indicates that the whole complex of pre-denervation circumstances, including animal sex, strain and the associated functional status (and not denervation method) determined the actual pressure response.

Remarkably, no BP increase was reported from similar earlier studies. It was suggested that under basal experimental conditions intrarenal receptors and afferent pathways did not exert a tonic inhibitory influence on the cardiovascular centers involved (Stella and Zanchetti 1991).

Although after unilateral denervation an increase in efferent RSNA to the contralateral kidney is a regular finding (reno-renal reflex), this was not usually associated with a decrease in RBF or GFR (Colindres et al. 1980, DiBona and Rios 1980, Golin et al. 1987). In our experiments, after unilateral denervation $\mathrm{CBF}$ of the contralateral kidney tended to increase rather than decrease, perhaps because of a denervation-dependent decrease in plasma Ang II activity or simply following an increase in BP (imperfect autoregulation). After the second denervation, in rats on LS and STD diet ipsilateral $\mathrm{CBF}$ increased further, an expected result of elimination of sympathetic vasoconstrictor input to the kidney; such response was also observed in our earlier experiments 
using the same denervation technique (KompanowskaJezierska et al. 2001). Interestingly, no such increase was observed in HS rats, possibly because under baseline conditions the renal circulation was here under dominating vasodilator influence of $\mathrm{NO}$, as indicated by a decrease in CBF after NOS blockade (Table 2).

Role of sodium intake, ROS and nNOS: the background for hypertensive response to renal denervation

The post-DNX elevation of BP was minimal in STD rats but pronounced in those on high or low sodium intake. It will be noticed that the common feature of both conditions is enhanced oxidative stress: at low sodium intake this is largely mediated by high plasma Ang II activity (Majid and Kopkan 2007). High sodium intake induces oxidative stress by mechanisms that are still being evaluated; there is also evidence that in rats on high-salt diet ROS generation is increased in kidney tissue (Kitiyakara et al. 2003, Wilcox 2005).

Local oxidative stress might increase stimulation of intrarenal chemoreceptors, enhance the inhibitory afferent traffic and lower the activity of sympathetic vasomotor centers. Under such baseline conditions, DNX (strictly: de-afferentation) i.e. release of the centers from the pronounced inhibition might be more effective than without enhanced oxidative stress. It must be admitted, however, that because of the diversity of intrarenal chemo- and mechanoreceptor types, individual afferent fibers might conduct both inhibitory and excitatory signals so that the final effect on sympathetic cardiovascular centers is difficult to predict, depending, for instance, on the actual baseline metabolic and functional status. The stress level would probably be lower in rats on STD diet, hence relatively modest BP increase in rats of this group.

Baseline conditions of our experiments, including anesthesia, extensive traumatic surgery and increased or decreased dietary sodium intake, were the probable factors promoting the development of oxidative stress. To check the hypothesis that high ROS activity was the necessary background for the pressor response to DNX, we repeated experiments in rats pretreated with tempol, a scavenger of superoxide radicals.

Tempol treatment did not affect BP per se, irrespective of sodium intake (Table 1). The increase in CBF suggests that under conditions of our experiments increased $\mathrm{O}_{2^{-}}$activity induced tonic intrarenal vasoconstriction. However, this effect was not seen in HS rats even though their kidneys are expected to be in the state of pronounced oxidative stress (Majid and Kopkan 2007). As suggested earlier, most probably local NO activity was here the dominating factor responsible for vasodilatation and high perfusion.

Under tempol treatment the post-DNX elevation of BP was abolished in LS rats and reverted to a significant decrease in HS rats in which the original hypertensive response was most pronounced, which confirmed the crucial role of the oxidative stress. As discussed earlier, of critical importance for the hypertensive response might be high ROS activity in the kidney. However, since tempol was administered intravenously, the present studies do not provide the basis to define the relative contribution of the effects of superoxide scavenging in the kidney, in the brain sympathetic centers and in target vascular tissues.

There were good reasons to suspect that nitric oxide (NO) status might be an important co-determinant of the BP response to DNX. NO specifically inhibits the sympathetic cardiovascular centers (Sakuma et al. 1992, Hansen et al. 1994, Hakim et al. 1995, Zanzinger 1999, Pintérová et al. 2011) and antagonizes ROS in most tissues, including the brain, kidney, peripheral vessels and the heart; this is observed both in normotensive animals and in rat models of hypertension (Golin et al. 1987, Zicha et al. 2001, Wilcox 2005). Of the two constitutive NO synthases, nNOS and NO derived from this isoform are particularly likely to be involved in the reflex control of cardiovascular functions and blood pressure. First, nNOS is the main source of NO in the brain (Bredt et al. 1990). Second, compared to eNOS, it can easier undergo uncoupling under oxidative stress, and generate ROS rather than NO (Sun et al. 2008). Indeed, in the diabetic kidney nNOS was reported to be a major if not the main source of ROS (Edlund et al. 2010). Therefore we examined how previous inhibition of this isoform with L-NPA would affect the BP response to DNX.

We saw that L-NPA did not change baseline BP, in agreement with other studies in which this inhibitor was used in rats on normal (Kakoki et al. 2001, Vaněčková et al. 2002) or high sodium diet (Walkowska and Johns, unpublished observations). On the other hand, L-NPA treatment reverted the post-denervation increase in BP in HS and STD rats to a significant decrease; only a modest increase in BP was seen in the LS group. The mechanism of the blockade of the increase may be complex. The inhibitory influence of the renal afferent sympathetic traffic is transmitted via the nucleus tractus 
solitarii to the neurons of the paraventricular nucleus (PVN). There is good evidence that release of NO by nNOS located in PVN mitigates the center's firing activity, which might inhibit the vasomotor function of sympathetic centers, such as rostral ventrolateral medulla (Li et al. 2003), local nNOS-derived NO was also found to buffer the rise in arterial pressure in $2 \mathrm{~K} 1 \mathrm{C}$ hypertensive rats (Rossi et al. 2010). Therefore, a deficit of NO mediator induced in our rats by L-NPA would cut off this influence and thereby prevent BP elevation after de-afferentation as observed in untreated rats.

Another reason for the blockade by L-NPA of the blood pressure response to DNX relates to the observation that in oxidative stress uncoupled nNOS in the kidney generates large amounts of ROS (Edlund et al. 2010). Therefore, blockade of this NOS isoform would have consequences similar as those of tempol treatment.

Taken together, these results strongly suggest that acute BP elevation after DNX was triggered by a release of brain sympatho-excitatory centers from the inhibitory influence of afferent impulse traffic from the kidneys, followed by increased sympathetic stimulation of target vascular tissues and widespread vasoconstriction. Additional studies involving measurements of sympathetic nerve activity (e.g. muscle SNA) would be needed to verify the hypothesis. Thereafter, it would be crucial to check if MSNA response to denervation is inhibited by ablation of the nucleus tractus solitarii or ganglionic blockade. A high level of oxidative stress, especially in the kidney, seems a necessary condition for the pressor response: previous reduction of the oxidative stress with tempol prevents the increase in BP after DNX. The response is also prevented by elimination of nNOS-derived NO, a likely mediator of the inhibition of the sympathetic centers by renal afferent traffic and also an important source of ROS in the kidney. The study helps understand some new aspects of interaction of the sympathetic nervous system and the enzymes generating ROS and NO in control of cardiovascular functions and blood pressure.

The present results showing acute BP rise refer exclusively to the earliest post-DNX period and by no means undermine the utility of catheter-based renal sympathetic denervation successfully used for treatment of refractory hypertension (Symplicity HTN-1 Investigators 2011). No serious early adverse effects of radiofrequency nerve ablations were reported until quite recently: four out of a group of 12 patients subjected to the procedure had to be temporarily transferred to an emergency unit because of "severe hypertensive episodes" (Brinkmann et al. 2012). It can be speculated that this occurred in patients with pronounced oxidative stress or endothelial dysfunction, which rendered them particularly sensitive to de-afferentation.

\section{Conflict of Interest}

There is no conflict of interest.

\section{Acknowledgements}

We are indebted to Professor Peter Bie, in whose department (Institute of Molecular Medicine, University of Southern Denmark, Odense, Denmark) renin assays were performed. Supported by the Polish Ministry of Science and Higher Education (grant NN401108038).

\begin{abstract}
Abbreviations
BP, blood pressure; CBF, cortical blood flow; DNX, renal denervation; HS, high-sodium diet; IMBF, inner medullary blood flow; L-NPA, N(omega)-propyl-Larginine; LS, low-sodium diet; NO, nitric oxide; OMBF, outer medullary blood flow; ROS, reactive oxygen species; RSNA, renal sympathetic nerve activity; RVLM, rostral ventrolateral medulla; SOD, superoxide dismutase; Tempol, 4-hydroxy-Tempo.
\end{abstract}

\section{References}

BIE P: Blood volume, blood pressure and total body sodium: internal signaling and output control. Acta Physiol 195: 187-196, 2009.

BREDT DS, HWANG PM, SNYDER SH: Localization of nitric oxide synthase indicating a neural role for nitric oxide. Nature 347: 768-770, 1990.

BRINKMANN J, HEUSSER K, SCHMIDT BM, MENNE J, KLEIN G, BAUERSACHS J, HALLER H, SWEEP FC, DIEDRICH A, JORDAN J, TANK J: Catheter-based renal nerve ablation and centrally generated sympathetic activity in difficult-to-control hypertensive patients: prospective case series. Hypertension 60: 1485-1490, 2012. 
CAMPESE VM, KOGOSOV I: Renal afferent denervation prevents hypertension in rats with chronic renal failure. Hypertension 25: 878-882, 1995.

COLINDRES RE, SPIELMAN WS, MOSS NG, HARRINGTON WW, GOTTSCHALK CW: Functional evidence for renorenal reflexes in the rat. Am J Physiol 239: F265-F270, 1980.

DIBONA GF, KOPP UC: Neural control of renal function. Physiol Rev 77: 75-197, 1997.

DIBONA GF, RIOS LL: Renal nerves in compensatory renal response to contralateral renal denervation. Am J Physiol 238: F26-F30, 1980.

DITTING T, FREISINGER W, SIEGEL K, FIEDLER C, SMALL L, NEUHUBER W, HEINLEIN S, REEH PW, SCHMIEDER RE, VEELKEN R: Tonic postganglionic sympathetic inhibition induced by afferent renal nerves? Hypertension 59: 467-476, 2012.

EDLUND J, FASCHING A, LISS P, HANSELL P, PALM F: The roles of NADPH-oxidase and nNOS for the increased oxidative stress and oxygen consumption in the diabetic kidney. Diabetes Metab Res Rev 26: 349$356,2010$.

GOLIN R, GENOVESI S, STELLA A, ZANCHETTI A: Afferent pathways of neural reno-renal reflexes controlling sodium and water excretion in the cat. J Hypertens 5: 417-424, 1987.

HAKIM MA, HIROOKA Y, COLEMAN MJ, BENNETT MR, DAMPNEY RAL: Evidence for a critical role of nitric oxide in the tonic excitation of rabbit renal sympathetic preganglionic neurones. $J$ Physiol 482: 401-407, 1995.

HANSEN J, JACOBSEN TN, VICTOR RG: Is nitric oxide involved in the tonic inhibition of central sympathetic outflow in humans? Hypertension 24: 439-444, 1994.

HERMAN NL, KOSTREVA DR: Alterations in cardiac $\left[{ }^{14} \mathrm{C}\right]$ deoxyglucose uptake induced by two renal afferent stimuli. Am J Physiol 251: R867-R877, 1986.

JACOB F, ARIZAP, OSBORN JW: Renal denervation chronically lowers arterial pressure independent of dietary sodium intake in normal rats. Am J Physiol 284: H2302-H2310, 2003.

KAKOKI M, ZOU AP, MATTSON DL: The influence of nitric oxide synthase 1 on blood flow and interstitial nitric oxide in the kidney. Am J Physiol 281: R91-R97, 2001.

KITIYAKARA C, CHABRASHVILI T, CHEN Y, BLAU J, KARBER A, ASLAM S, WELCH WJ, WILCOX CS: Salt intake, oxidative stress, and renal expression of NADPH oxidase and superoxide dismutase. J Am Soc Nephrol 14: 2775-2782, 2003.

KLINE RL, STUART PJ, MERCER PF: Effect of renal denervation on arterial pressure and renal norepinephrine concentration in Wistar-Kyoto and spontaneously hypertensive rats. Can J Physiol Pharmacol 58: 1384-1388, 1980.

KOMPANOWSKA-JEZIERSKA E, WALKOWSKA A, JOHNS EJ, SADOWSKI J: Early effects of renal denervation in the anaesthetised rat: natriuresis and increased cortical blood flow. J Physiol 531: 527-534, 2001.

KOMPANOWSKA-JEZIERSKA E, WOLFF H, KUCZERISZKA M, GRAMSBERGEN JB, WALKOWSKA A, JOHNS EJ, BIE P: Renal nerves and nNOS: role in natriuresis of acute sodium loading in conscious rats. Am $J$ Physiol 94: R1130-R1139, 2008.

LAPPE RW, WEBB RL, BRODY MJ: Selective destruction of renal afferent versus efferent nerves in rats. Am $J$ Physiol 249: R634-R637, 1985.

LI Y, ZHANG W, STERN JE: Nitric oxide inhibits the firing activity of hypothalamic paraventricular neurons that innervate the medulla oblongata: role of GABA. Neuroscience 118: 585-601, 2003.

LIARD JF: Renal denervation delays blood pressure increase in the spontaneously hypertensive rats. Experientia 15: 339-340, 1977.

MAJID DS, KOPKAN L: Nitric oxide and superoxide interactions in the kidney and their implication in the development of salt-sensitive hypertension. Clin Exp Pharmacol Physiol 34: 946-952, 2007.

PINTÉROVÁ M, KUNEŠ J, ZICHA J: Altered neural and vascular mechanisms in hypertension. Physiol Res 60: 381402, 2011.

POULSEN K, JORGENSEN J: An easy radioimmunological microassay of renin activity, concentration and substrate in human and animal plasma and tissues based on angiotensin I trapping by antibody. J Clin Endocrinol Metab 39: 816-825, 1974. 
ROSSI NF, MALISZEWSKA-SCISŁO M, CHEN H, BLACK SM, SHARMA S, RAVIKOV R, AUGUSTYNIAK RA: Neuronal nitric oxide synthase within paraventricular nucleus: blood pressure and baroreflex in two-kidney, one clip hypertensive rats. Exp Physiol 95: 845-857, 2010.

SAKUMA I, TOGASHI H, YOSHIOKA M, SAITO H, YANAGODA M, KOBAYASHI T, YASUDA H, GROSS SS, LEVI R: NG-methyl-L-arginine, an inhibitor of L-arginine-derived nitric oxide synthesis, stimulates renal sympathetic nerve activity in vivo. A role for nitric oxide in the central regulation of sympathetic tone? Circ Res 70: 607-611, 1992.

STELLA A, ZANCHETTI A: Functional role of renal afferents. Physiol Rev 71: 659-682, 1991.

SUN J, DRUHAN LJ, ZWEITER JL: Dose dependent effects of reactive oxygen and nitrogen species on the function of neuronal nitric oxide synthase. Arch Biochem Biophys 471: 126-133, 2008.

SYMPLICITY HTN-1 INVESTIGATORS: Catheter-based renal sympathetic denervation for resistant hypertension: durability of blood pressure reduction out to 24 months. Hypertension 57: 911-917, 2011.

VANĚČKOVÁ I, KRAMER HJ, MALÝ J, BÄCKER A, BOKEMEYER D, ČERVENKA L: Lack of a role of neuronal nitric oxide synthase in the regulation of the renal function in rats fed a low-sodium diet. Kidney Blood Press Res 25: 224-231, 2002.

VANHOUTTE PM, SHIMOKAWA H, TANG EHC, FELETOU M: Endothelial dysfunction and vascular disease. Acta Physiol (Oxf) 196: 193-222, 2009.

WEBB RL, BRODY MJ: Functional identification of the central projections of afferent renal nerves. Clin Exp Hypertens A 9 (Suppl 1): 47-57, 1987.

WILCOX CS: Oxidative stress and nitric oxide deficiency in the kidney: a critical link to hypertension? Am J Physiol 289: R913-R935, 2005.

WINTERNITZ SR, KATHOLI RE, OPARIL S: Role of the renal sympathetic nerves in the development and maintenance of hypertension in the spontaneously hypertensive rat. J Clin Invest 66: 971-978, 1980.

WYSS JM, OPARIL S, SRIPAIROJTHIKOON W: Neuronal control of the kidney: contribution to hypertension. Can $J$ Physiol Pharmacol 70: 759-770, 1992.

XU H, FINK GD, CHEN A, WATTS S, GALLIGAN JJ: Nitric oxide-independent effects of tempol on sympathetic nerve activity and blood pressure in normotensive rats. Am J Physiol 281: H975-H980, 2001.

ZANZINGER J: Role of nitric oxide in the neural control of cardiovascular function. Cardiovasc Res 43: 639-649, 1999.

ZICHA J, DOBEŠOVÁ Z, KUNEŠ J: Relative deficiency of nitric oxide-dependent vasodilation in salt-hypertensive Dahl rats: the possible role of superoxide anions. J Hypertens 19: 247-254, 2001. 